\title{
QUANTITATIVE DERMATOGLYPHIC STUDY OF THE FINGER RIDGE COUNT IN BREAST CARCINOMA PATIENTS FROM NORTHEASTERN BULGARIA
}

\author{
Galina Yaneva ${ }^{1}$, Tsonka Dimitrova ${ }^{1}$, Djeni Cherneva ${ }^{1}$, Nikoleta Ivanova ${ }^{1}$, Neli Fialkovska ${ }^{1}$, \\ Ivan Vachkov' ${ }^{1}$, Stefan Sivkov ${ }^{2}$, Dobry Ivanov ${ }^{1}$ \\ ${ }^{1}$ Department of Biology, Faculty of Pharmacy, Medical University of Varna \\ ${ }^{2}$ Department of Anatomy, Histology and Embryology, Faculty of Medicine, \\ Medical University of Plovdiv
}

\begin{abstract}
The present study aimed to assess the relationship between the results from a quantitative dermatoglyphic analysis of the finger ridge count and the predisposition for developing breast cancer.

The fingerprints of 82 breast carcinoma female patients diagnosed by histological and mammographic investigations were obtained and compared to 60 female controls from Northeastern Bulgaria. The fingerprints were obtained by classical ink method. The finger ridge count was determined by the method of Cummins and Midlo.

The total finger ridge count (TFRC) showed statistically significant difference between the patients and the controls on the first and second finger of the right hand and on the second and third finger of the left hand. Due to statistically significant differences of TFRC on some of the fingers, we discovered differences in the descending formulas in the two observed groups. Descending formulas on the fingers of the breast carcinoma patients compared with the controls on the left hand were respectively $2>4>1>5>3$ vs $2>1>4>5>3$, and on the right hand $1>2>4>3>5$ vs $4>1>3>2>5$, respectively. Statistical significance was examined by SPSS 18.0 software.
\end{abstract}

Our data indicated that a dermatoglyphic analysis could be utilized as a fast inexpensive supportive screening tool for the early diagnostics of breast cancer.

Keywords: dermatoglyphics, breast cancer, total finger ridge count (TFRC)

\footnotetext{
Address for correspondence:

Galina Yaneva

Faculty of Pharmacy

Medical University of Varna

84 Tsar Osvoboditel Blvd

9000, Varna, Bulgaria

e-mail:galina.yaneva@mu-varna.bg
}

Received: February 8, 2018

Accepted: May 14, 2018 


\section{INTRODUCTION}

People can easily find on the fingers of their hands narrow ridges called papillary lines which form unique configurations inherent only to them and nobody else (1). These ridges are subject to change up to the 17th gestation week and the fingerprint patterns remain unchanged for the rest of that individual's life. Anomalies in the formation of the finger papillary configurations may occur during the formation of the dermal ridges in the third or fourth prenatal month (2). One of the most important quantitative dermatoglyphic parameters is the finger ridge count. The ridge count consists of the number of the ridges which cross or touch the straight line, drawn from the triradius to the center of the pattern. The triradius is a papillary pattern where three streams of ridges meet.

Breast cancer is a malignant tumor which can be hereditary or sporadic. Sporadic forms develop due to environmental factors which cause genetic changes in somatic cells without specific genetic predisposition for the disease. It is considered that hereditary breast carcinoma is caused most often by germinative mutations in highly penetrant genes BRCA1 and BRCA2 (3).

\section{AIM}

The purpose of the current research is to determine the quantitative dermatoglyphic parameters with prognostic and screening value by identifying significant differences in the total finger ridge count (TFRC) in breast carcinoma patients compared to healthy controls.

\section{MATERIALS AND METHODS}

In the period 2015-2016 a research was conducted among 82 female patients from Northeastern Bulgaria, aged 35-65 years, diagnosed with breast cancer by histological and mammographic investigations in the Thoracic Surgery Clinic at St. Marina Hospital in Varna. Simultaneously 60 age-matched healthy controls were also selected with no personal or familial history of diagnosed breast cancer and the observations were recorded. The fingerprints were taken in a passive manner and the rolling method for printing on a high-quality paper was applied (4). We started with the fifth finger on the right hand and finished with the fifth finger on the left hand. Statistical significance was examined by SPSS 18.0 software.

\section{RESULTS AND DISCUSSION}

The values of the finger ridge count are to a significant degree dependent on the fingertip papillary pattern type. Ridge zero means presence of arches, low ridge count is seen in little loops and rarely in little whorl patterns. High ridge count corresponds to whorl patterns, although large loops (Fig.1), (Fig.2) are not rare either.

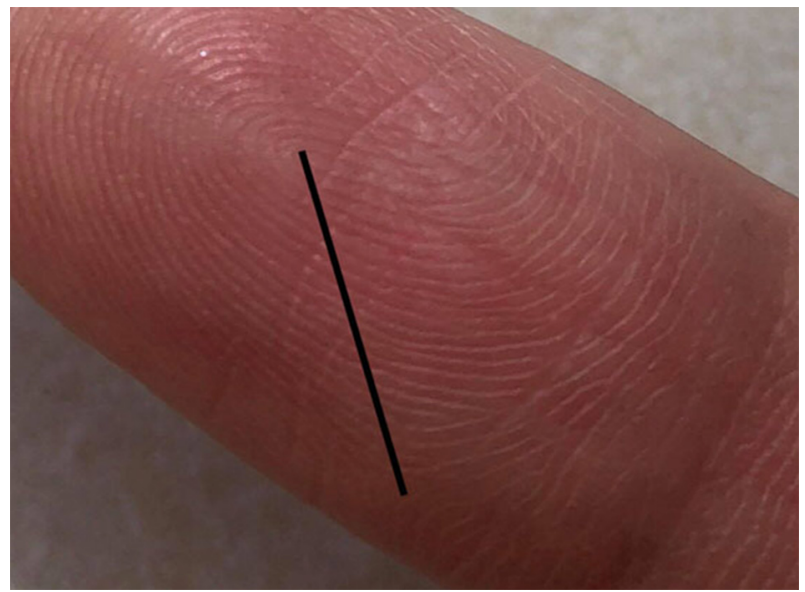

Fig. 1. Finger ridge count and its estimation in a loop

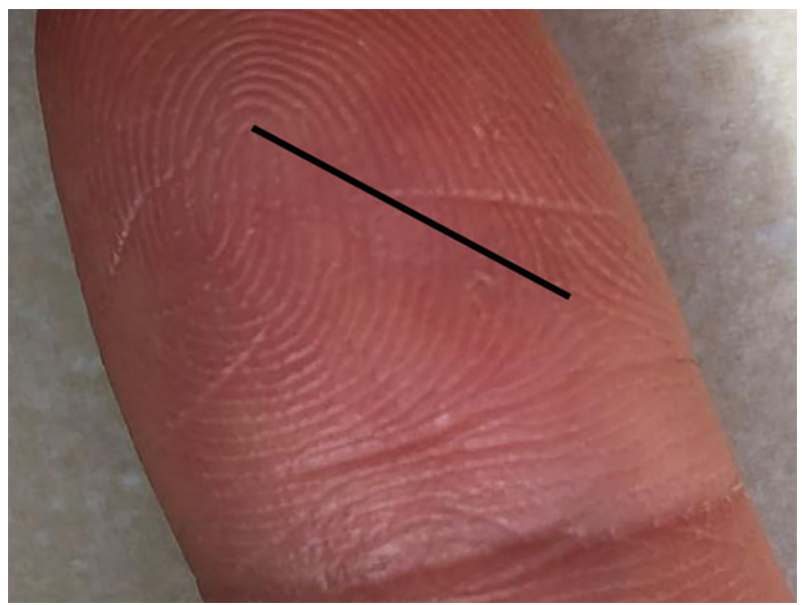

Fig. 2. Finger ridge count and its estimation in a whorl

Results for both hands are presented on Fig. 3 where ridges were predominantly seen on the second fingers, followed by the third fingers on the left hand of breast carcinoma patients. Especially high ridge count was observed on the second fingers. There was a slight difference on the first and fourth fingers, fol- 


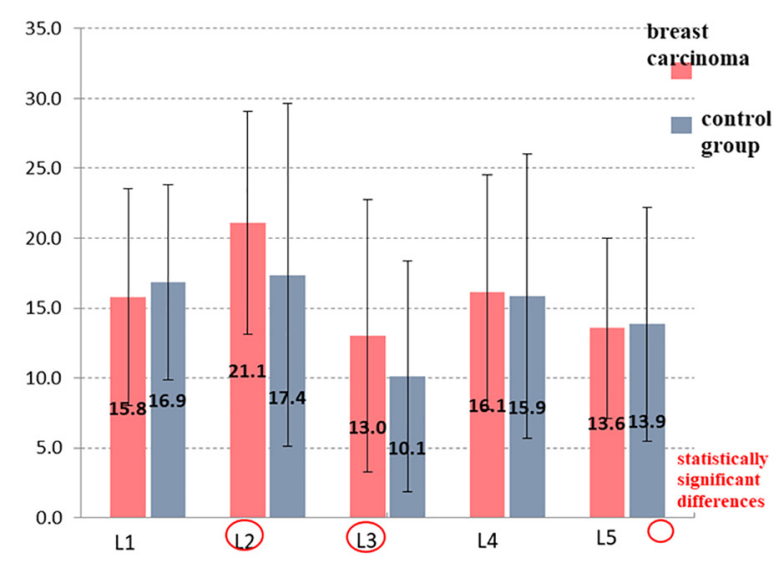

Fig. 3. Ridge count mean value and standard deviation on the left hand in breast carcinoma patients and in the control group

lowed by the fifth homologous fingers, where the slight difference was in favor of the fifth homologous fingers. In the control group, the highest ridge count was on the left hand on the second fingers, followed by the first, fourth and fifth fingers. The third pair of homologous fingers has the lowest values.

When comparing the finger ridge count in breast carcinoma patients and the control group by the Mann-Whitney test, we established statistically significant differences on the second $(\mathrm{p}<0.05)$ and third fingers $(\mathrm{p}<0.05)$ of the left hand.

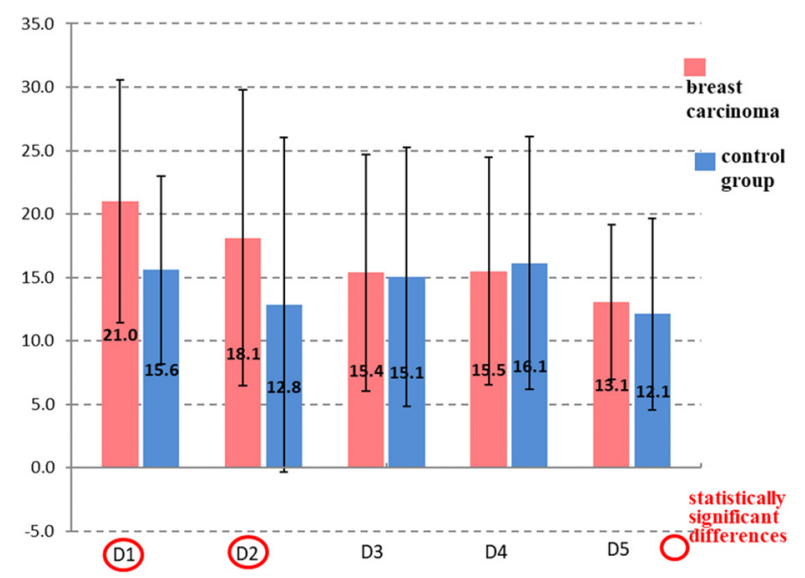

Fig. 4. Ridge count mean value and standard deviation on the right hand in breast carcinoma patients and control group

The right hand of the patients with breast carcinoma was characterized by significantly higher ridge count on the first and second fingers. Ridge count on the third and fourth homologous fingers showed almost equal values. The fifth fingers revealed the lowest values.

In women from the control group, the highest ridge count on the right hand was observed on the fourth fingers. Ridge count on the first and third homologous fingers resulted in almost equal values, a similar ratio was observed on the third and the fifth fingers.

When comparing the finger ridge count in breast carcinoma patients and the control group by the Mann-Whitney test, we established statistically significant differences on the first $(\mathrm{p}<0.001)$ and second fingers $(p<0.05)$ of the right hand.

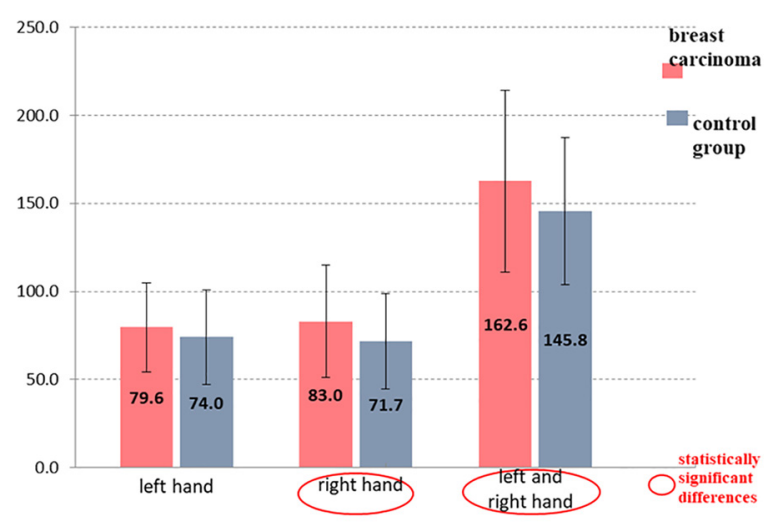

Fig. 5. TFRC mean value and standard deviation on left and right hand in breast carcinoma patients and control group

The bilateral comparison showed that the mean value of TFRC on the patients' right hand was higher than on their left hand, similar data are reported from different researches $(5,6)$.

The estimated mean value of TFRC on the left hand of breast carcinoma patients was 79.6 and for the controls it was 74.0. For the right hand the corresponding values were 83.0 and 71.7. On both hands the values were 162.6 and 145.8. Statistically significant differences in the mean TFRC values were estimated for the right hand $(\mathrm{p}<0.05)$ as well as for both hands $(\mathrm{p}<0.05)$. Due to statistically significant differences of TFRC on some of the fingers, we observed differences in the descending formulas in the two observed groups. Descending formulas for distribution of the ridge count on the fingers of the breast 
carcinoma patients and the controls on the left hand were respectively $2>4>1>5>3$ vs. $2>1>4>5>3$, and on the right hand were $1>2>4>3>5$ vs. $4>1>3>2>5$, respectively.

The results of the current study suggest that breast carcinoma patients and the control group may be differentiated according to their dermatoglyphic status. Dermatoglyphic differences of the breast carcinoma patients and the normal population could be due to the change in the relative frequency of the normal genes controlling the formation of the fingertip patterns (7-10). According to Holt (1961) the ridge count is determined by a small number of non-dominant additive genes (11). The increase in the TFRC of breast carcinoma patients could be due to the relatively higher frequency of the genes for high ridge count, compared to the control group (12).

Based on the theories of the genetic role in the development of the breast cancer, a similar difference in gene frequency seems logical. The expression and the penetrance of a single gene could be modified by pure genetic or epigenetic factors (3). Following this logic, we hypothesized that genes encoding the finger ridge count might have a modifying effect on the genes linked to the development of breast cancer. According to this hypothesis, the higher the difference in TFRC, the higher the expressivity and the penetrance of the modifying genes. A certain level in the polygenic system has to be passed over (3) for breast cancer to develop. On the other hand, an increase in the expressivity of certain genes could reduce the natural ability of the organism to neutralize harmful influences and to increase the aberrant ontogenetic effects, caused by specific genes in specific organs.

It is assumed that the changes in the finger ridge count allow us to look for a pleiotropic effect of genes determining breast cancer. The differences in the expressivity and penetrance of these genes presuppose differences in the power of the influence of the external factors, which may be taking place in the development of the disease (12).

Women with breast carcinoma were characterized by a higher finger ridge count compared to the control group and this abnormality was caused by changes developing before the fourth prenatal month. Pathology after the fourth prenatal month cannot change the skin pattern and this way the ab- normalities in epidermal ridges are caused by prenatal exogenic factors or by a genetic disease as breast cancer which develops in the first trimester. Higher values of the TFRC may be accepted as an indicator for the violation of the genetic control of the formation of the papillary patterns in breast carcinoma patients and for a certain violation in the homeostasis in their organism. In conclusion, we consider that at present the criteria for breast cancer diagnosis by dermatoglyphic investigation are insufficient, but there is a common pathogenetic mechanism causing the development of the disease and the changes in the dermatoglyphic status.

\section{CONCLUSION}

Our data shows a significant difference in the total finger ridges count in the right and left hands of the cases with breast cancer compared with the normal controls. These findings suggest that digital dermatoglyphics may have a future role in identifying women at increased risk for breast cancer. The dermatoglyphics method is simple, inexpensive and may be used as a reliable indicator in screening for early indication of malignancy.

\section{REFERENCES}

1. Cummins H, Midlo C. Finger prints palms and soles. An introduction in dermatoglyphics. Dover Publications. 1961.

2. Abel W. Kritische Studien über die Entwicklung der Papillarmuster auf den Fingerbeeren. Z Mensch Vererb Kons. 1938; 21: 497-529.

3. Toncheva D, Gavrilov I. Contemporary standards for evaluation and treatment of familial predispositions to breast and ovary carcinoma. Clinical behavior in breast cancer. Study book. Varna. Art Traser; 2013. p. 25-6.

4. Purvis-Smith SG. Finger and palm printing technique for clinician. Med J Aust. 1969; 2(4):189-91.

5. Raizada A, Johri V, Ramnath T, Chowdhary D, Garg RA. Cross-sectional study on the palmar dermatoglyphics in relation to carcinoma breast patients. J Clin Diagn Res. 2013;7(4):609-12. doi: 10.7860/JCDR/2013/4689.2864.

6. Huang CM, Mi MP. Digital dermal patterns in breast cancer. Proc Natl Sci Counc Repub China B. 1987; 11(2):133-6. 
7. Inamdar VV, Vaidya SA, Kulkarni P, Devarshi DB, Kulkarni S, Tungikar SL. Dermatoglyphics in carcinoma cervix. J Anat Soc India. 2006; 55(1):57-9.

8. Sridevi NS, Silvia Delphine, Wilma CR, Kulkarni $\mathrm{R}$, Seshagiri C. Palmar dermatoglyphics in carcinoma breast of Indian women. Rom J Morphol Embryol. 2010; 51(3):547-50.

9. Oladipo GS., Paul CW, Bob-Manuel IF, Fawehinmi HB, Edibamode EI. Study of digital and palmar dermatoglyphic patterns of Nigerian women with malignant mammary neoplasm. J Appl Biosci. 2009; (15): 829 - 34.

10. Penrose L. Memorandum of dermatoglyphics nomenclature. Birth defect original article series. 1968; 4(3): 10-38.

11. Holt S. Inheritance of dermal ridge patterns. In: Penrose L, editor. Recent advances in human genetics. London: Churchill; 1961. p. 101.

12. Sivkov S, Akabaliev VH, Kaleva NN. Comparative dermatoglyphic study of schizophrenic patients evidence of the neurodevelopmental model of schizophrenia. Folia Medica. 2009; 51(3): 25-30. 